\title{
Antitumor effects of dioscin in A431 cells via adjusting ATM/p53-mediated cell apoptosis, DNA damage and migration
}

\author{
PENG WANG, CHUN WANG and CHUNYING LIU \\ College of Pharmacy, Liaoning University of Traditional Chinese Medicine, Shenyang, Liaoning 110847, P.R. China
}

Received January 24, 2020; Accepted October 26, 2020

DOI: $10.3892 / \mathrm{ol} .2020 .12321$

\begin{abstract}
Skin cancer is the deadliest type of malignant disease and causes primary mortality worldwide. Dioscin, which exists in medicinal plants, has potent anticancer effects. However, its effects on skin cancer remain unknown. In the present study, the activity and mechanism of dioscin on the human skin cancer A431 cell line were investigated, MTT, colony formation, Transwell, wound-healing, TUNEL, Comet, immunofluorescence and western blot assays were used to assess the effects of dioscin on A431 cells. The results of MTT, colony formation, Transwell and wound-healing assays revealed that dioscin suppressed proliferation, colony formation and invasion of the cancer cells. TUNEL and comet assays demonstrated that dioscin exhibited significant effects on cell apoptosis and DNA damage. Investigations into the mechanism revealed that the expression levels of phosphorylated Ataxia telangiectasia-mutated (ATM) were considerably activated by dioscin, which significantly upregulated the expression levels of p53 to activate mitochondrial apoptosis signaling. Furthermore, the expression levels of BAX, cleaved caspase-3/9 and cleaved poly (ADP-ribose) polymerase were upregulated, and the expression levels of BCL-2 were downregulated by dioscin. Additionally, dioscin markedly downregulated the expression levels of matrix metalloproteinase 2 (MMP2), MMP9, RHO and cdc42, which are all associated with tumor invasion. In addition, p53-small interfering RNA transfection experiments indicated that dioscin exhibited excellent activity against skin cancer in vitro by decreasing p53 expression. Overall, the present results suggested that dioscin inhibited skin cancer cell proliferation via adjusting ATM/p53-mediated cell apoptosis, migration and DNA damage, which should be considered as a potential option for future treatments of skin cancer.
\end{abstract}

Correspondence to: Professor Chunying Liu, College of Pharmacy, Liaoning University of Traditional Chinese Medicine, 79 Chongshan Eastern Road, Shenyang, Liaoning 110847, P.R. China

E-mail: 15841160153@163.com

Key words: dioscin, skin cancer, p53 signal, cell apoptosis, DNA damage

\section{Introduction}

Skin cancer is one of the major causes of cancer-associated mortality in humans, with 232,000 new cases worldwide in 2012, resulting in 55,000 deaths (1) There are two major types of non-melanoma skin cancer, named basal cell carcinoma and squamous cell carcinoma (SCC) (1,2). A number of known chemical carcinogens, such as arsenide, and exposure to hazardous UV rays can cause the development of SCC through mediation of free radical production, resulting in a healthy epithelial cell being transformed in a malignant one $(3,4)$. As the prevalence of skin cancer is increasing, with skin cancer having the fastest-growing cancer incidence among all malignancies in recent years with an annual growth rate of 3-5\% per year, it is necessary to investigate the molecular mechanisms underlying SCC and develop novel treatment options for therapies (4). However, it is well known that chemotherapy drugs for patients with skin cancer are highly toxic compounds that target fast-growing healthy cells and have numerous side effects. Therefore, investigation into novel drugs with high efficiency and low toxicity for the treatment of skin cancer is highly important.

Apoptosis is a process whereby dysregulated cells in the body are removed and the balance is maintained between the generation of new cells and the removal of old ones (5). Cell adhesion to the extracellular matrix serves a key role in the regulation of cellular migration, proliferation and differentiation, which is controlled by important regulators for cell adhesion and migration, such as matrix metalloproteinases (MMPs) (6). It has been reported that polyphenols can generate reactive oxygen species (ROS) in cancer cells, leading to the induction of apoptosis, as well as downregulation of proliferation and migration via the modulation of several signaling pathways, such as the EGFR/MAPK signaling pathways, and MMPs, suggesting that cell apoptosis and migration serve key roles in cancer regulation and prevention (7). Mitochondria are important organelles of energy production and survival signaling cascades, as well as cell death (8). Mitochondrial-associated abnormalities may be associated with an imbalance of mitochondrial metabolism and the enhancement of antimitochondrial apoptosis (8). Mitochondrial apoptosis is also known as intrinsic apoptosis (8). Previous studies have indicated that decreased mitochondrial membrane potential can induce apoptosis and increase ROS levels in colorectal cancer cells, suggesting that the mitochondrial apoptotic pathway serves a pivotal role in the initiation and progression of cancer $(9,10)$. 
The p53 signaling pathway, which is composed of numerous genes, responds to multiple stress signals by inducing apoptosis, cell senescence or cell cycle arrest, allowing to prevent or repair damage (11). Previous studies revealed that the p53 signaling pathway is closely associated with the development of SCC and epigenetic abnormalities in this process $(12,13)$. Ataxia telangiectasia-mutated (ATM) is a phosphoinositide 3-kinase-related kinase associated with cellular processes, including cell proliferation and DNA repair (14). ATM expression is induced by DNA damage, where ATM undergoes auto-phosphorylation on Ser1981 and is recruited to sites of DNA damage, where it initiates a signaling cascade through multiple DNA damage response proteins, including p53 and other ligases (15). A previous study revealed that shallots and licorice induce apoptosis through the induction of ATM/p53 signaling in human cervical carcinoma HeLa cells, suggesting that ATM/p53 signaling may promote or prevent the development of cancer (16). However, to the best of our knowledge, there is no evidence on whether ATM/p53 signaling can regulate apoptosis and DNA damage in skin cancer.

Traditional Chinese medicines (TCMs), which are rich in biologically active metabolites with low toxicity, are widely used in the clinic for healthcare and disease control (17). Some natural products, including matrine and flavonolignans from medicinal plants, have potent effects against skin cancer $(18,19)$. Therefore, it is reasonable to seek effective natural products from TCMs to treat skin cancer. Dioscin (Fig. 1A), an active natural product from numerous medicinal plants, has exhibited potent activity against liver damage and renal injury (20-30), as well as antioxidant and anti-inflammatory effects in previous studies, including antifungal, antiviral, hypoglycemic and immune regulatory effects $(31,32)$. Increasing efforts have been made to investigate the anticancer activities of dioscin on several types of human cancer cell lines, such as Hep-2, SMM7721 and PC3 cells (12,33-37). An increasing amount of evidence has revealed that dioscin can inhibit tumor cell metastasis in lung cancer, breast cancer, melanoma and laryngeal cancer $(38,39)$. A mechanistic study revealed that dioscin exerts an antimetastatic effect through connexin 43, suppressing tumor cell malignancy and activating macrophage sensitivity in melanoma (39). In addition, targeted daunorubicin and dioscin co-delivery liposomes can increase the inhibitory effects of daunorubicin on A549 cells and decrease tumor metastasis by downregulation of MMP2 and TGF- $\beta$ (40). However, to the best of our knowledge, there are currently no studies on the anticancer effects of dioscin on A431 cells, and the mechanisms underlying the action of dioscin against skin cancer remain unknown. Therefore, the aim of the present study was to investigate the effects of dioscin against skin cancer and its potential mechanisms in A4431 cells in vitro.

\section{Materials and methods}

Chemicals and reagents. Dioscin was obtained from the Chengdu Research Institute of Biology of the Chinese Academy of Sciences. MTT was obtained from Roche Diagnostics. The Protein Extraction kit, penicillin and streptomycin were purchased from Nanjing KeyGen Biotech Co., Ltd. The BCA protein assay kit was obtained from Beyotime
Institute of Biotechnology. Carboxymethylcellulose-Na, Tris and SDS were purchased from Sigma-Aldrich (Merck KGaA). The Dulbecco's modified Eagle's medium (DMEM) and fetal bovine serum (FBS) were obtained from Gibco (Thermo Fisher Scientific, Inc.). DAPI was purchased from Sigma-Aldrich (Merck KGaA). The comet assay kit was purchased from Cell Biolabs, Inc. The terminal deoxynucleotidyl transferase dUTP nick-end labeling (TUNEL) assay was performed using the TransDetect ${ }^{\circledR}$ In situ Fluorescein TUNEL Cell Apoptosis Detection kit (TransGen Biotech Co., Ltd.). Primary antibodies were purchased from ProteinTech Group, Inc., and Wuhan Boster Biological Technology, Ltd. (Table SI). Secondary antibodies were purchased from ProteinTech Group, Inc. Lipofectamine ${ }^{\circledR} 2000$ was purchased from Thermo Fisher Scientific, Inc., and p53 small interfering (si) RNAs were purchased from Guangzhou RiboBio Co., Ltd. Z-VAD-FMK/pan-caspase inhibitor was purchased from MedChemExpress.

Cell lines and culture. The human skin carcinoma A431 cell line was purchased from Wuhan Boster Biological Technology, Ltd. The A431 cells were cultured in DMEM with 10\% FBS, supplemented with $100 \mathrm{U} / \mathrm{ml}$ penicillin and $100 \mathrm{~g} / \mathrm{ml}$ streptomycin, in a humidified $5 \% \mathrm{CO}_{2}$ atmosphere at $37^{\circ} \mathrm{C}$.

MTT assay. The cells were plated in 96-well plates $\left(5 \times 10^{4}\right.$ cells/well) and incubated at $37^{\circ} \mathrm{C}$ for $24 \mathrm{~h}$. After $100 \mu \mathrm{l}$ of medium was removed, various concentrations of dioscin $(0.0,0.7,1.4,2.9,5.8$ or $11.6 \mu \mathrm{M})$ were added into the plates and then incubated for 6,12 or $24 \mathrm{~h}$ at $37^{\circ} \mathrm{C}$. Subsequently, $10 \mu \mathrm{l}$ MTT stock solution $(5 \mathrm{mg} / \mathrm{ml})$ was added, and the plates were incubated for another $4 \mathrm{~h}$ at $37^{\circ} \mathrm{C}$. The formazan crystals were dissolved using $150 \mu \mathrm{lDMSO}(150 \mu \mathrm{l} /$ well). The absorbance was measured using a microplate reader (Thermo Fisher Scientific, Inc.) at $490 \mathrm{~nm}$, and the cell morphology was observed using a phase contrast light microscope (Nikon Corporation) with bright-field at x200 magnification.

Colony-forming assay. A total of 500 cells/well were seeded into 6-well plates. The cells were treated with dioscin $(0.0,2.9$, 5.8 or $11.6 \mu \mathrm{M}$ ) for 3 days, and after treatment the drugs were replaced with medium. The treated cells were maintained in culture medium for 10 days. Finally, the cells were stained with $0.1 \%$ crystal violet at room temperature for $20 \mathrm{~min}$ and $>50$ cells were considered as a colony. The colony formation numbers were analyzed using ImageJ Software v1.3 (National Institutes of Health).

Wound-healing assay. A431 cells were plated into 6-well plates at $3 \times 10^{5}$ cells/well and cultured for $24 \mathrm{~h}$ at $37^{\circ} \mathrm{C}$. Wounds were scratched using a pipette tip and washed with PBS to remove detached cells in serum-free medium. The cells were treated with dioscin $(0.0,2.9,5.8$ and $11.6 \mu \mathrm{M})$ at $37^{\circ} \mathrm{C}$ for $24 \mathrm{~h}$. After the dead cells were washed away with PBS, the migration images were captured using a bright-field light microscope at x200 magnification and analyzed using ImageJ Software v1.3 (National Institutes of Health).

Transwell invasion assay. The invasion of A431 cells was measured using $8-\mu \mathrm{m}$ Transwell chambers and the filter 

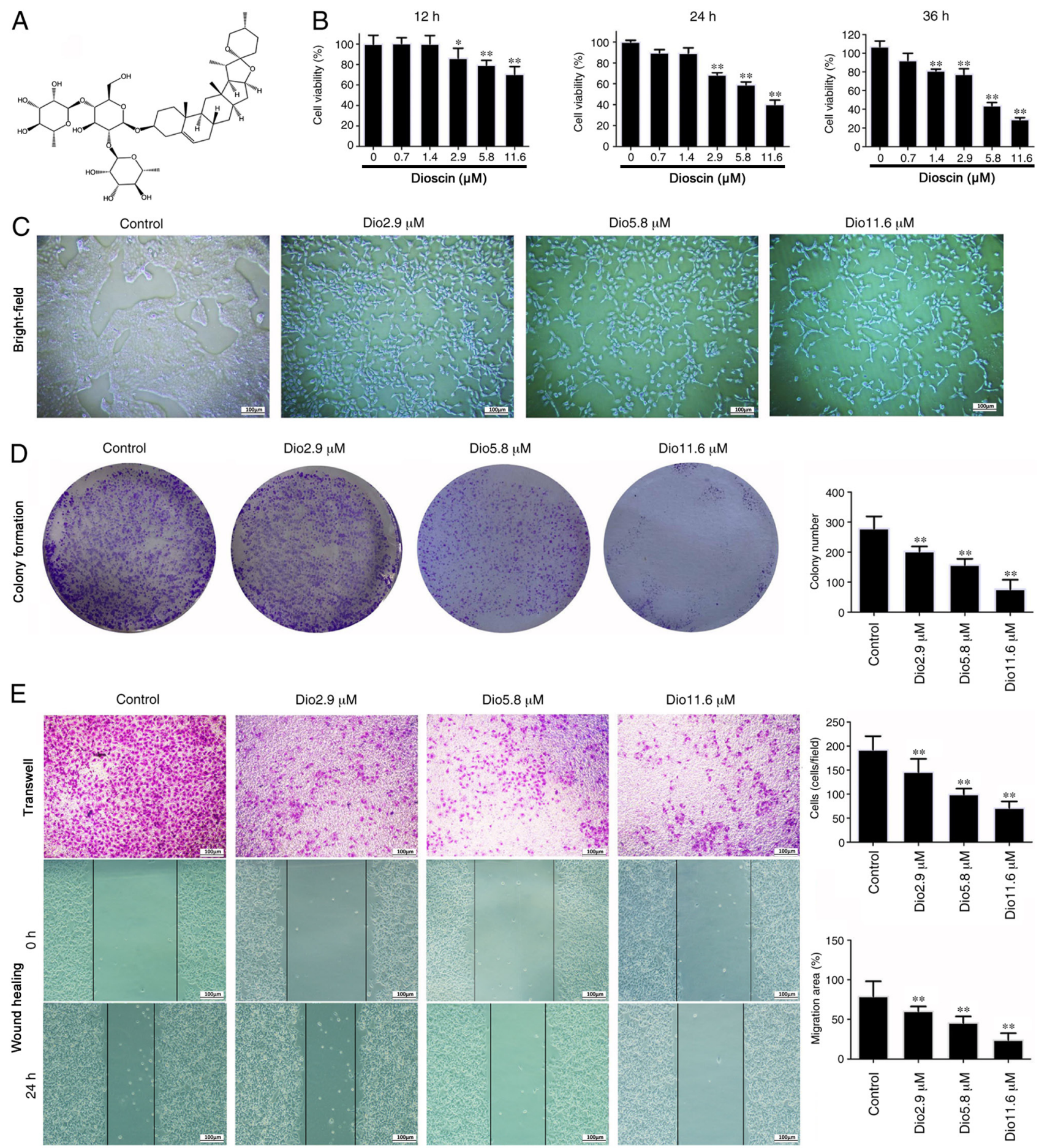

Figure 1. Inhibitory effects of dioscin on the viability, colony formation and migration of A431 cells. (A) Chemical structure of dioscin. (B) Effects of dioscin on the viability of A431 cells detected via MTT assay. (C) Representative morphological images of cells treated with different concentrations of dioscin (2.9, 5.8 and $11.6 \mu \mathrm{M}$ ) for $24 \mathrm{~h}$. (D) Effects of dioscin treatment (2.9, 5.8 and $11.6 \mu \mathrm{M}$ ) for $24 \mathrm{~h}$ on colony formation in A431 cells. (E) Effects of dioscin treatment $(2.9,5.8$ and $11.6 \mu \mathrm{M})$ for $24 \mathrm{~h}$ on migratory and invasive properties of A431. Scale bar, $100 \mu \mathrm{m}$. Data are presented as the mean $\pm \mathrm{SD}(\mathrm{n}=5)$. ${ }^{*} \mathrm{P}<0.05$ and ${ }^{* * *} \mathrm{P}<0.01$ vs. control. Dio, dioscin.

membrane was coated with $60 \mu 1$ Matrigel at $37^{\circ} \mathrm{C}$ for $24 \mathrm{~h}$ (BD Biosciences). A total of $6 \times 10^{4}$ cells in serum-free medium $(200 \mu \mathrm{l})$ were added into the top invasion chambers, while the lower chamber was filled with $500 \mu 1$ medium containing 15\% FBS. After incubation with dioscin (0.0, 2.9, 5.8 and $11.6 \mu \mathrm{M}$ ) at $37^{\circ} \mathrm{C}$ for $24 \mathrm{~h}$, the cells were fixed with $4 \%$ formaldehyde at $37^{\circ} \mathrm{C}$ for 20 min and stained with hematoxylin at $37^{\circ} \mathrm{C}$ for $20 \mathrm{~min}$. A phase-contrast light microscope
(Nikon Corporation) was used to count cells in five randomly selected fields at x200 magnification.

TUNEL assay. Cell apoptosis was analyzed using the TransDetect ${ }^{\circledR}$ In situ Fluorescein TUNEL Cell Apoptosis Detection kit based on the manufacturer's protocol. A431 cells in 24-well plates were washed with PBS, fixed with $4 \%$ paraformaldehyde at $37^{\circ} \mathrm{C}$ for $20 \mathrm{~min}$ and permeabilized with 
$0.5 \%$ Triton-100. Subsequently, $150 \mu 1$ green fluorescein-labeled dUTP solution was added on the surface of samples and incubated at $37^{\circ} \mathrm{C}$ for $1 \mathrm{~h}$. Then, $50 \mu 150 \%$ glycerinum was used as the mounting medium. Finally, the images were captured using a fluorescence microscope (Olympus Corporation; magnification, x200) and cells were counted under the microscope in five random fields. The data were analyzed using ImageJ Software v1.4 (National Institutes of Health).

Comet assay. The extent of DNA damage was determined using the Comet assay kit according to the manufacturer's protocol (Cell Biolabs, Inc.). A total of $2 \times 10^{5}$ cells/well of A431 cells were incubated in 6-well plates. After being treated with different concentrations of dioscin $(2.9,5.8$ and $11.6 \mu \mathrm{M})$ at $37^{\circ} \mathrm{C}$ for $24 \mathrm{~h}$, cell images were captured using a fluorescence microscope at x200 magnification (Olympus Corporation). Finally, the Comet Assay Software Project v1.2.2 (CaspLab) was used to analyze the selected cells (50 cells from each of the two replicate slides).

Immunofluorescence assay. A431 cells were incubated in a moist chamber at $4^{\circ} \mathrm{C}$. After pretreatment, the cells were fixed with $4 \%$ paraformaldehyde for $20 \mathrm{~min}$ at $37^{\circ} \mathrm{C}$ and incubated with $3 \%$ BSA (Beijing Solarbio Science \& Technology Co., Ltd.) for $2 \mathrm{~h}$ at $37^{\circ} \mathrm{C}$. Subsequently, the cells were incubated overnight with rabbit anti-p53, cleaved PARP and cleaved-caspase-3 antibodies (1:1,00), and p-ATM (1:50) (Table SI). After washing with PBS three times, the samples were incubated with a FITC-conjugated goat anti-rabbit IgG (1:2,000; cat. no. SA00001-2; ProteinTech Group, Inc.) at $37^{\circ} \mathrm{C}$ for $1 \mathrm{~h}$, and then the cell nuclei were stained with DAPI $(5 \mu \mathrm{g} / \mathrm{ml})$ at $37^{\circ} \mathrm{C}$ for $24 \mathrm{~h}$. The sample images were captured using a fluorescence microscope (Olympus Corporation) at a magnification of $\mathrm{x} 200$.

Western blot assay. The proteins from A431 cells treated with dioscin $\left(0,2.9,5.8\right.$ and $11.6 \mu \mathrm{M}$ at $37^{\circ} \mathrm{C}$ for $\left.24 \mathrm{~h}\right)$ were extracted using the Protein Extraction kit. After measuring the protein concentrations using the BCA protein assay kit, $50 \mu \mathrm{g} /$ lane of protein samples were separated via 10-15\% SDS-PAGE and transferred to a PVDF membrane (EMD Millipore). Subsequently, the membranes were incubated with $5 \%$ milk for $3 \mathrm{~h}$ at $37^{\circ} \mathrm{C}$ and were then incubated with primary antibodies (Table SI) at $4^{\circ} \mathrm{C}$ overnight, followed by incubation with horseradish peroxidase-conjugated secondary antibody (1:2,000; cat. no. SA00001-2; ProteinTech Group, Inc.) for $2 \mathrm{~h}$ at room temperature. Finally, detection of protein bands was performed using an enhanced chemiluminescence system on a ChemiDoc XRS imaging system (Bio-Rad Laboratories, Inc.), and the data were normalized to GAPDH expression and analyzed using GraphPad Prism 6.01 (GraphPad Software, Inc.). The protein bands were quantified using ImageJ Software v1.4 (National Institutes of Health).

Inhibition of p53 and caspase experiments. A431 cells ( $2 \times 10^{5}$ cells/well) were plated in 6 -well plates for $24 \mathrm{~h} 37^{\circ} \mathrm{C}$. For inhibition of caspase, the cells were pretreated with $20 \mu \mathrm{M}$ Z-VAD-FMK for $1 \mathrm{~h}$ at $37^{\circ} \mathrm{C}$ before addition of dioscin $(0,2.9$, 5.8 and $11.6 \mu \mathrm{M})$ at $37^{\circ} \mathrm{C}$ for $24 \mathrm{~h}$, and the expression levels of cleaved-caspase-3/9 were detected as aforementioned. For inhibition of p53, transfection was applied to knock down p53 expression using p53-targeted siRNAs (siRNA1, 5'-GCA CAGAGGAAGAGAAUCUTT-3'; siRNA2, 5'-GCGCACAGA GGAAGAGAAUTT-3'; siRNA3, 5'-GAAAUUUGCGUG UGGAGUATT-3') and a scrambled siRNA (5'-GCTTCGGCA GCACATATACTA-3'). Subsequently, p53-siRNA and transfection reagent (Lipofectamine ${ }^{\circledR} 2000$ ) were mixed for $20 \mathrm{~min}$. The A431 cells were then transfected at $37^{\circ} \mathrm{C}$ for $5 \mathrm{~h}$ with the siRNA liposomes in antibiotic-free cell medium. Finally, cell proliferation, apoptosis, colony formation and migration, and the expression levels of p53, procaspase-3/9, cleaved caspase-3/9, cleaved PARP, Bax, Bcl-2, RHO and cdc42 were detected as aforementioned. After $24 \mathrm{~h}$ of transfection, cells were treated with 11.6 $\mu \mathrm{M}$ dioscin or PBS for $24 \mathrm{~h}$.

Statistical analysis. GraphPad Prism 5.0 (GraphPad Software, Inc.) was used to analyze the data, which are presented as the mean \pm SD. Comparisons between 2 groups were performed using unpaired Student's t-test, while a one-way ANOVA followed by Tukey's post hoc test was used for multiple comparisons. $\mathrm{P}<0.05$ was considered to indicate a statistically significant difference.

\section{Results}

Cytotoxicity of dioscin in A431 cells. The MTT results demonstrated that dioscin treatment at the concentrations of 2.9, 5.8 and $11.6 \mu \mathrm{M}$ for $24 \mathrm{~h}$ significantly inhibited cell viability to 79,58 and $39 \%$, respectively, compared with the control (Fig. 1B). The viability rates at concentrations of 2.9, 5.8 and $11.6 \mu \mathrm{M}$ for $12 \mathrm{~h}$ were 81,78 and $65 \%$, respectively, while those for $36 \mathrm{~h}$ were 66,41 and $23 \%$, respectively (Fig. 1B). For subsequent experiments, cells were exposed to 2.9,5.8 and $11.6 \mu \mathrm{M}$ dioscin for $24 \mathrm{~h}$ as the change of inhibition rate was the most obvious. As presented in Fig. $1 \mathrm{C}$, bright-field images suggested that cell death was induced by dioscin.

Effects of dioscin on proliferation, invasion and migration of A431 cells. As presented in Fig. 1D, dioscin (2.9, 5.8 and $11.6 \mu \mathrm{M}$ ) significantly decreased colony formation in A431 cells compared with the control. Cell migration and invasion assays in Fig. 1E suggested that dioscin $(2.9,5.8$ and $11.6 \mu \mathrm{M})$ suppressed the invasive and migratory capabilities of A431 cells. In addition, the effects of wound-healing on A431 cells were significantly inhibited by dioscin $(2.9,5.8$ and $11.6 \mu \mathrm{M})$ in a dose-dependent manner. These results suggested that dioscin significantly inhibited the proliferation, migration and invasion of A431 cells.

Dioscin induces apoptosis and DNA damage in A431 cells. In order to investigate the inhibitory effects of dioscin on apoptosis, apoptosis was measured using a TUNEL assay. As presented in Fig. 2A, TUNEL-positive cells were significantly increased by dioscin compared with the control. In a comet assay, dioscin decreased the contents of head DNA and significantly increased the length of DNA migration smears (the comet tails) compared with the control group (Fig. 2A), which demonstrated that dioscin significantly caused DNA damage in A431 cells

Dioscin activates ATM autophosphorylation in vitro. In order to investigate the impact of dioscin on ATM, A431 cells were 
A
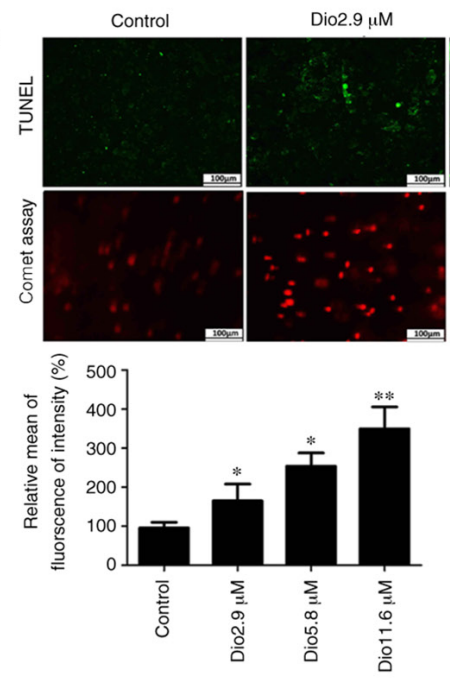

B
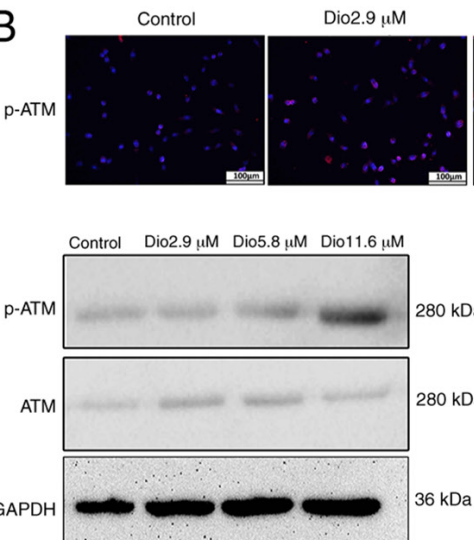

Dio5.8 $\mu \mathrm{M}$
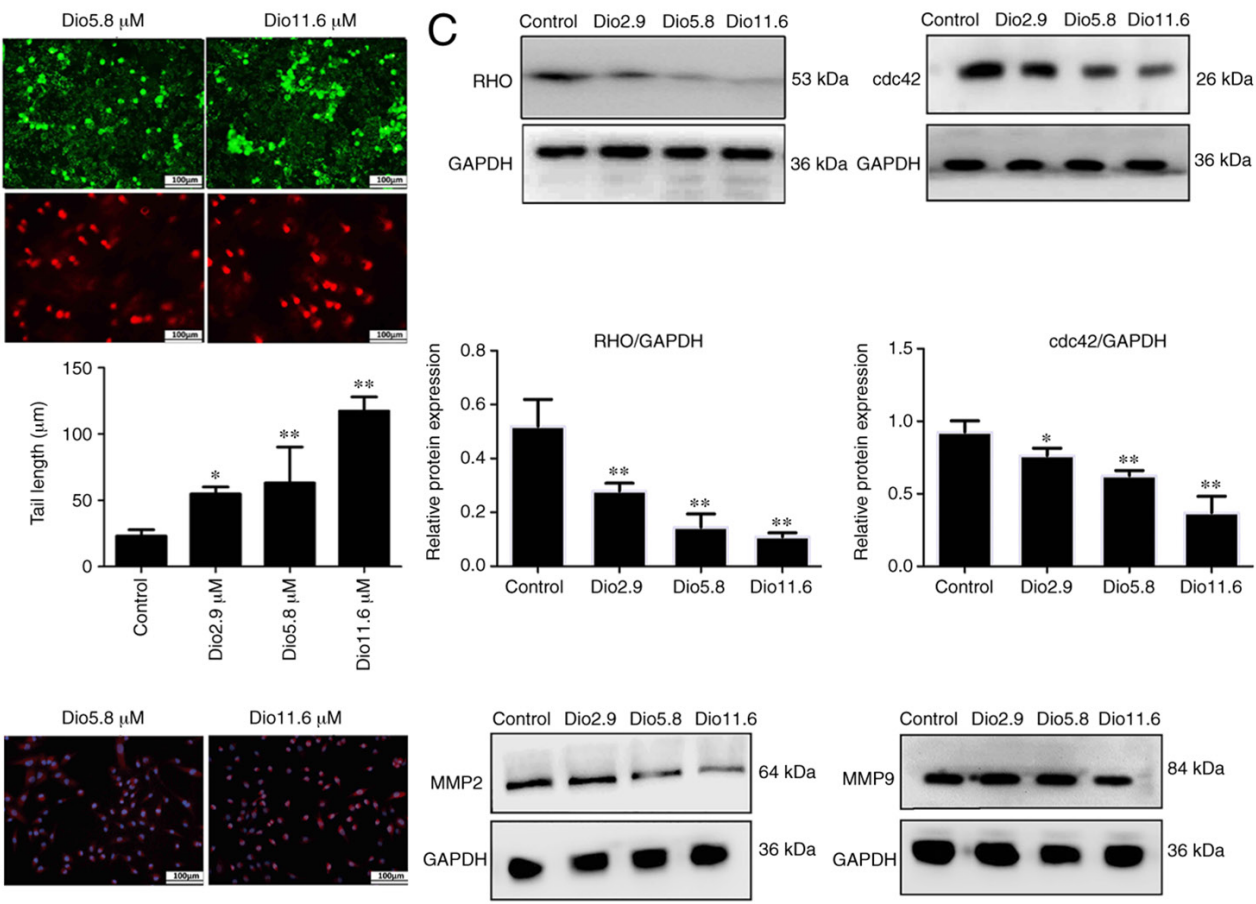

Figure 2. Dioscin induces apoptosis and DNA damage, and suppresses invasion and migration of A431 cells. (A) Representative figures of dioscin on apoptosis and DNA damage via TUNEL and comet assays, respectively. (B) Expression levels of p-ATM after dioscin treatment via immunofluorescence and western blotting. (C) Effects of dioscin on the expression levels of MMP2/9, RHO and cdc42. Data are presented as the mean \pm SD ( $\mathrm{n}=3$ ). ${ }^{*} \mathrm{P}<0.05$ and ${ }^{* *} \mathrm{P}<0.01 \mathrm{vs}$. control. Dio, dioscin; p-ATM, phosphorylated ataxia telangiectasia-mutated; MMP, matrix metalloproteinase; TUNEL, terminal deoxynucleotidyl transferase dUTP nick-end labeling.

treated with different concentrations of dioscin and the expression levels of p-ATM were assessed via immunofluorescence. The results presented in Fig. 2B indicated that, compared with the control group, p-ATM expression was increased by dioscin. In addition, the western blot analysis results indicated that 5.8 and $11.6 \mu \mathrm{M}$ dioscin significantly upregulated the expression levels of p-ATM compared with the control group (Fig. 2B).

Dioscin inhibits the expression levels of MMP2/9 and Rho GTPase family protein. As presented in Fig. 2C, dioscin significantly decreased the expression levels of MMP2/9, RHO and cdc42 compared with the control group. These results indicated that dioscin may suppress cell invasion and migration via inhibiting MMP2/9, RHO and cdc42 in human A431 cells.

Dioscin activates p53 signal pathway associated with cell apoptosis. As presented in Fig. 3A and B, immunofluorescence and western blot analysis revealed that the expression levels of p53, cleaved-PARP and cleaved-caspase-3 were significantly upregulated by dioscin compared with those in the control group. Furthermore, compared with the control group, dioscin significantly increased the expression levels of cleaved-caspase- 9 and Bax, and significantly inhibited Bcl-2 expression (Fig. 3B). These data suggested that dioscin may induce apoptosis of A431 cells via the p53 signaling pathway.

Effect of p53 siRNA and caspase inhibitor on dioscin-induced apoptosis, migration and DNA damage in cells. In order to investigate the effect of p53 in the anticancer activity of dioscin, p53-siRNA transfection experiments were performed in the present study. Knockdown of p53 was performed using 3 siRNAs, and p53 siRNA2 was selected for subsequent experiments since it induced the most significant decrease in p53 protein expression (Fig. S1). As presented in Fig. 4A, compared with the control group, dioscin significantly inhibited the viability of A431 cells, which was then ameliorated by 553 siRNA. Notably, compared with the dioscin group, the group treated with dioscin plus p53 siRNA exhibited increased viability of cancer cells, but this was not significantly different compared with the p53 siRNA group, which indicated that p53-siRNA restored the inhibitory effect of dioscin on A431 cells. Furthermore, p53 siRNA ameliorated the effects of dioscin on colony formation (Fig. 4B), migration and apoptosis in A431 cells (Figs. 4C and D and S2. Furthermore, the expression levels of p53, cleaved caspase-3/9, cleaved PARP and Bax were all notably decreased compared with 
A
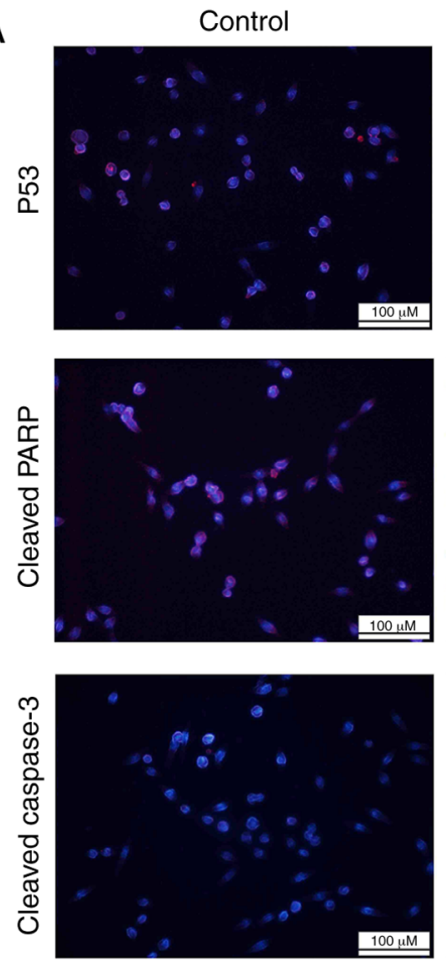

B

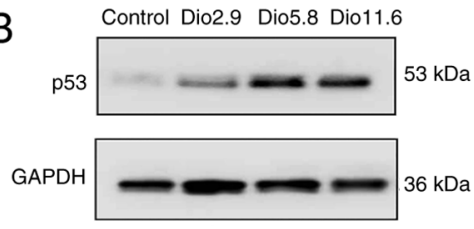

p53/GAPDH
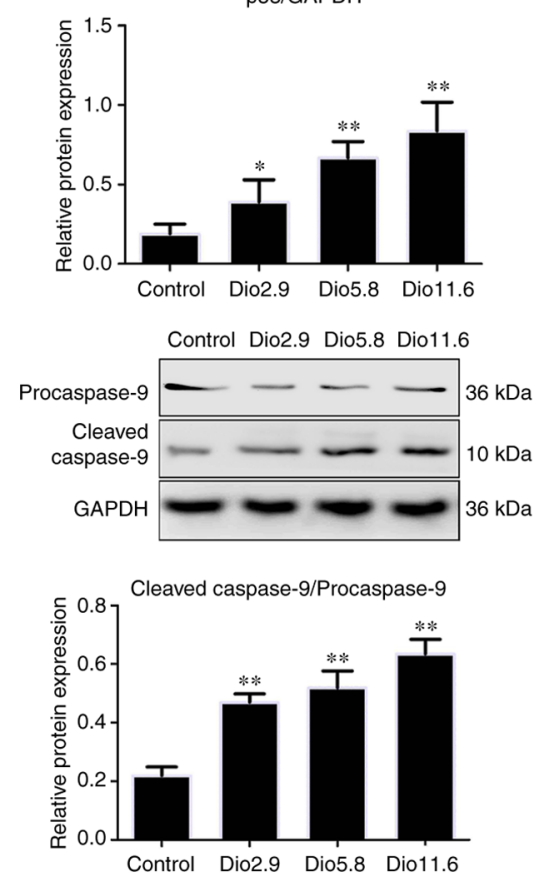
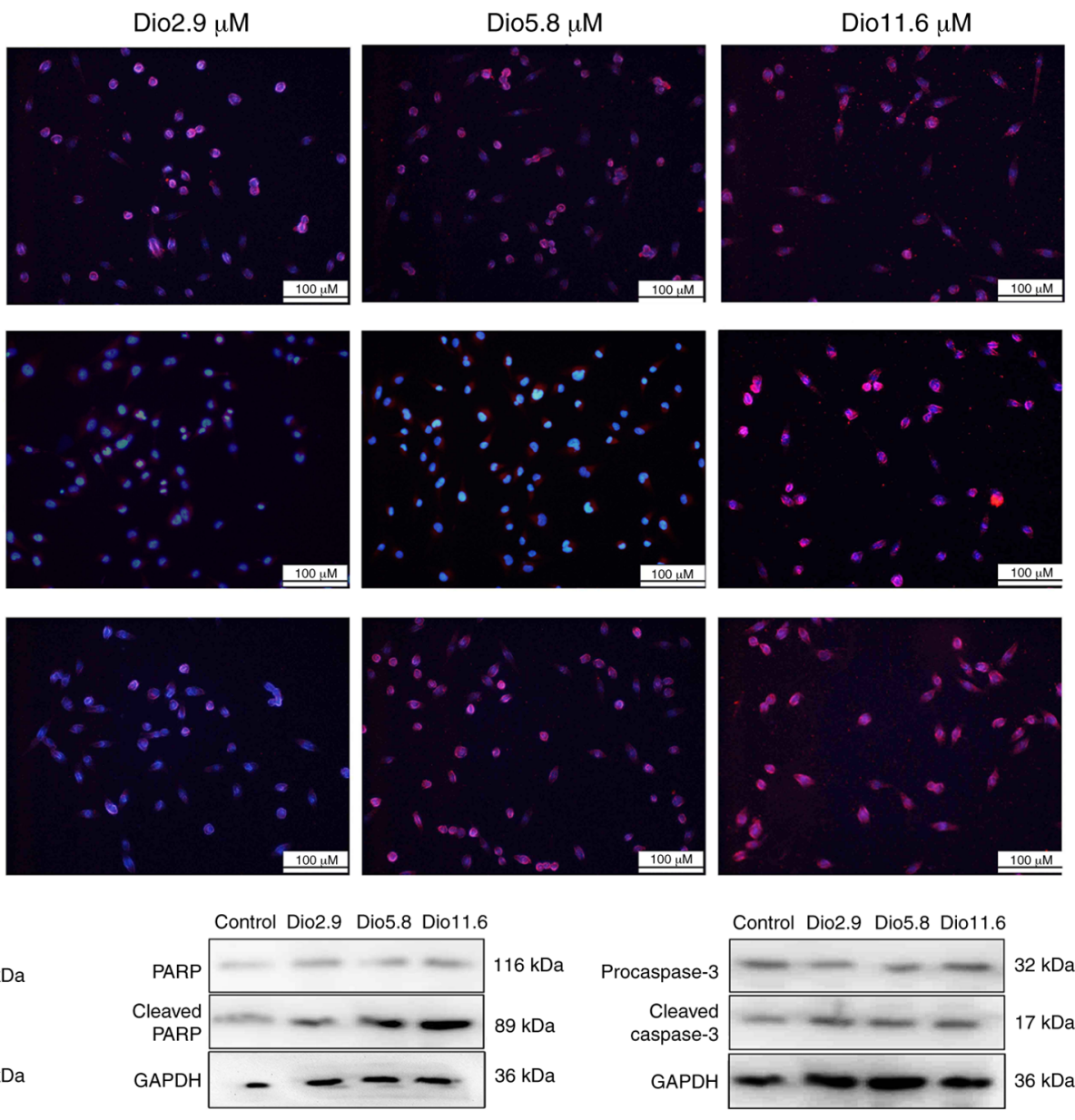

$100 \mu \mathrm{M}$
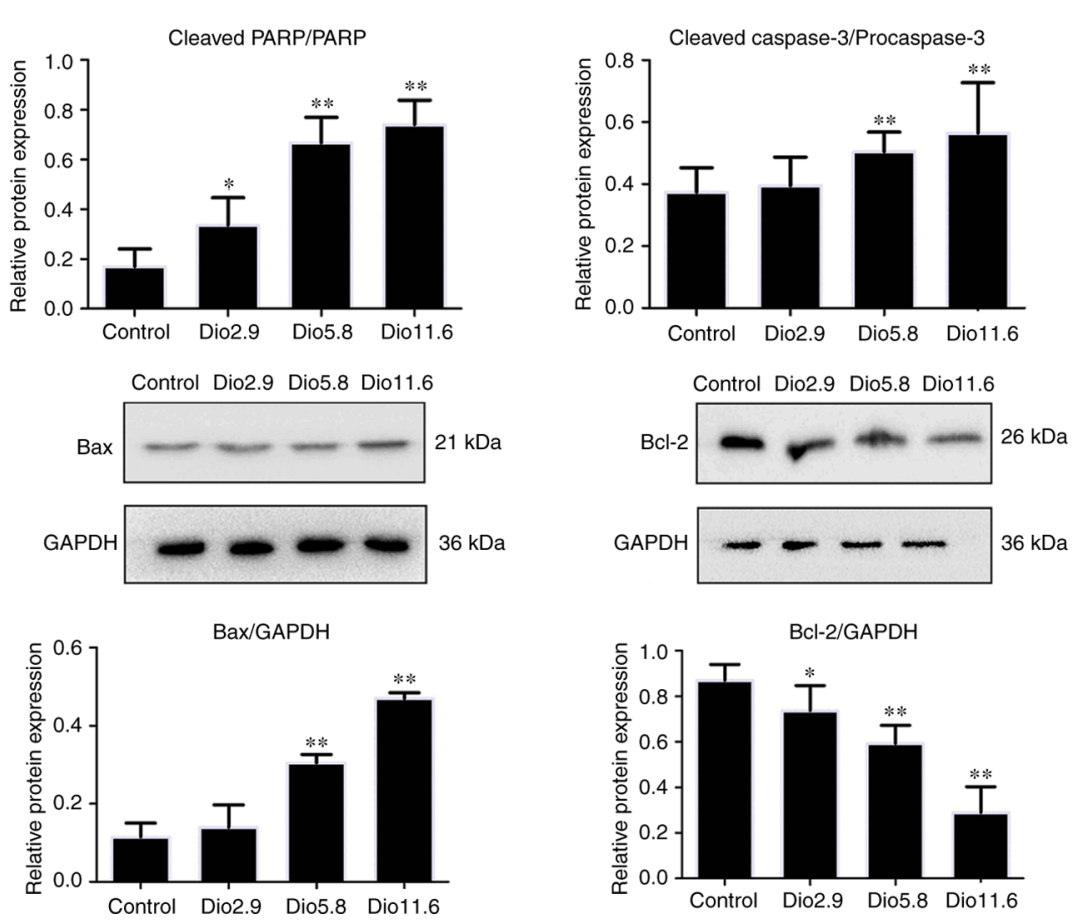

Figure 3. Dioscin activates the p53 signaling pathway associated with apoptosis. (A) Representative fluorescence images of p53 expression. (B) Effects of dioscin on the expression levels of $\mathrm{p} 53$, cleaved-PARP, cleaved caspase-3/9, Bax and $\mathrm{Bcl}-2$. Data are presented as the mean $\pm \mathrm{SD}$ ( $\mathrm{n}=3$ ). ${ }^{*} \mathrm{P}<0.05$ and ${ }^{* *} \mathrm{P}<0.01$ vs. control. Dio, dioscin; PARP, poly (ADP-ribose) polymerase.

the dioscin group, and the Bcl-2 expression level was markedly increased compared with the dioscin group, while the protein levels of RHO and cdc 42 were markedly upregulated following transfection with p53-siRNA with or without dioscin compared with the dioscin group (Fig. 4E). Additionally, the levels of caspase-3/9 were downregulated after treatment with 

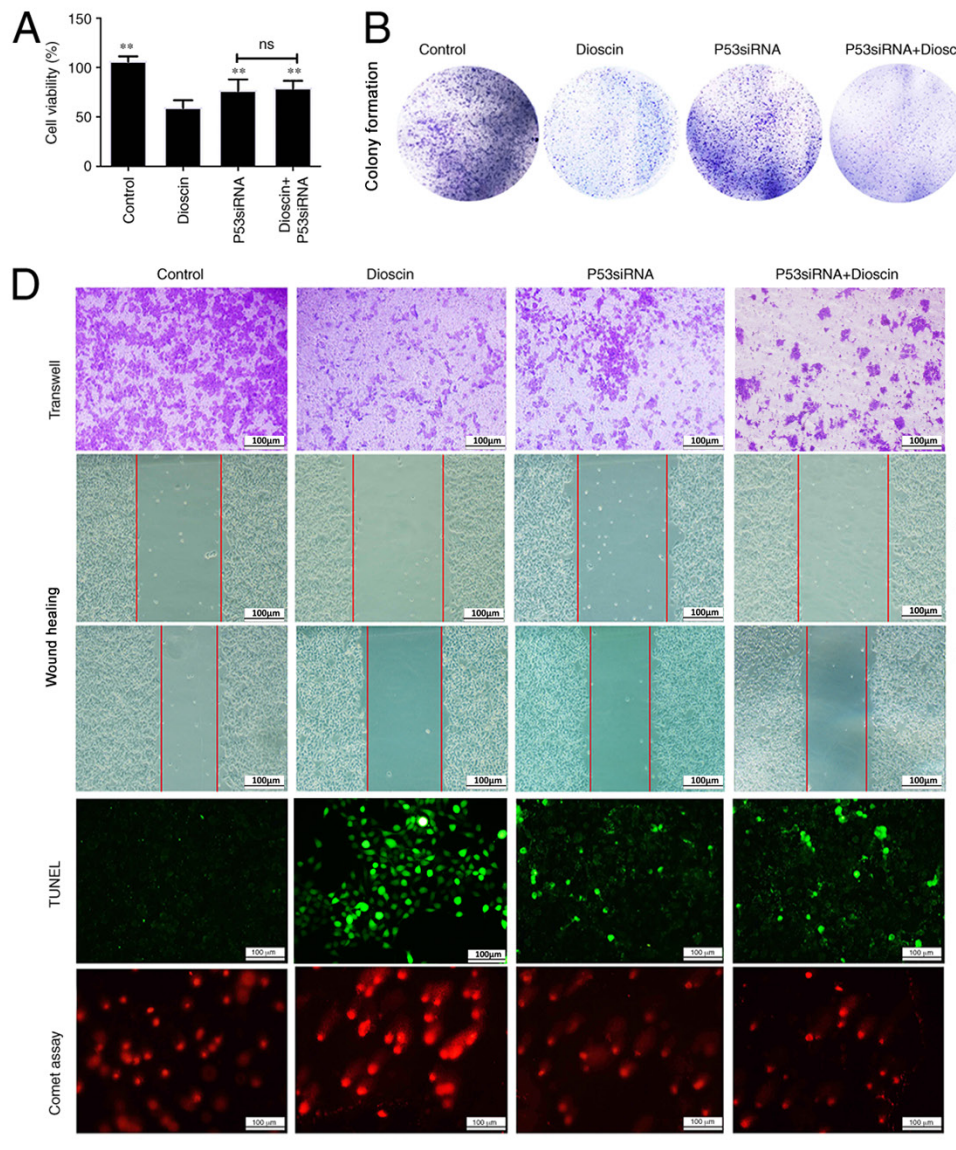

\section{C}
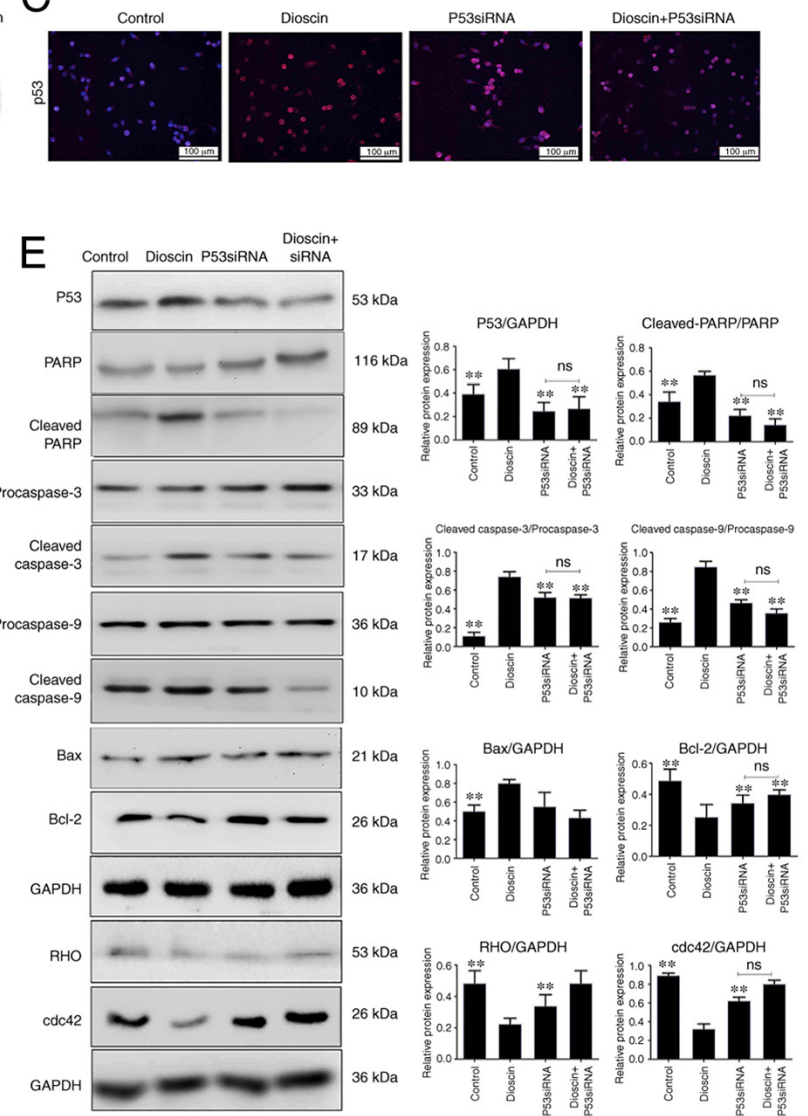

Figure 4. p53-siRNA abrogates the inhibitory effects of dioscin on A431 cells. (A) A431 cells were transfected with p53-siRNA and the viability of cells was measured. Effects of dioscin and p53-siRNA on (B) cell colony formation ability, (C) cell migration, apoptosis and DNA damage, (D) p53 expression via immunofluorescence and (E) protein expression levels of cleaved-PARP, cleaved caspase-3/9, Bax, Bcl-2, RHO and cdc42. Scale bar, 100 $\mu$ m. Data are presented as the mean $\pm \mathrm{SD}(\mathrm{n}=3)$. ${ }^{* *} \mathrm{P}<0.01$ vs. dioscin group. PARP, poly (ADP-ribose) polymerase; ns, not significant; siRNA, small interfering RNA.

Z-VAD compared with the dioscin group (Fig. S3). These data suggested that p53-siRNA transfection abrogated the effect of dioscin on the p53 signaling pathway.

\section{Discussion}

Skin cancer is one of the most prevalent malignancies in the world, and $\sim 20 \%$ of the population will develop skin cancer at some point during their lifetime (41). In recent years, as the specific pathogenesis of skin cancer remains unclear, and the clinical treatment of skin cancer is also limited, the incidence of skin cancer has been increasing by $3-5 \%$ per year (4). As an active ingredient in herbs, dioscin has been reported to exert beneficial actions against liver cancer, head and neck cancer, pancreatic cancer and lung cancer in previous studies $(13,36)$. In addition, it has been reported that dioscin-loaded mixed micelles exhibit antitumor activities, which may benefit from the significant increase in cellular uptake of dioscin in MCF-7 cancer cells, suggesting that dioscin-loaded mixed micelles may be a potential nano-drug delivery system for cancer chemotherapy (42). However, to the best of our knowledge, there is currently no study available that describes the anticancer effects of dioscin on skin cancer. Therefore, the inhibitory effect of dioscin on A431 cells was investigated in the present study, and the results demonstrated that cell proliferation and colony formation of A431 cells were markedly inhibited by dioscin. The current results suggested that dioscin may have the potential to treat skin cancer.

DNA damage response leads to DNA repair, which is closely associated with cell survival or cell death. The stress of DNA damage activates ATM signaling pathways, including ATM autophosphorylation and phosphorylation of p53 (43). p53 is a nuclear transcription factor that becomes stabilized and activated by a variety of cellular stresses, such as DNA damage, oxidative stress and hypoxia (44). Once activated, ATM phosphorylates various downstream molecules, such as p53 and $\mathrm{H} 2 \mathrm{AX}$, resulting in cell death (45). A study has reported that kaempferol induces ROS production, phosphorylation of ATM and activation of p53 protein levels (46). In the present study, the comet assay revealed that following dioscin treatment, the DNA content was transferred to the tail of the comet, suggesting that DNA damage was increased, and the number of apoptotic cells was increased by dioscin treatment. In addition, it was revealed that dioscin markedly upregulated the levels of p-ATM and p53 using western blotting and immunofluorescence assays. The present data indicated that dioscin had potent activity against skin cancer cells in vitro via regulating DNA damage and apoptosis.

Mitochondrial apoptotic signaling is important in apoptotic cell death. The BCL-2 family contains 2 classes of anti-apoptotic and pro-apoptotic members (47). BCL-2 is an anti-apoptotic member, while BAX is a pro-apoptotic member 
that is primarily distributed on the mitochondrial membrane, and the loss of mitochondrial membrane potential is closely associated with the release of cytochrome $c$ (48). Caspases are vital in cells for apoptosis. Activation of both the exogenous promoters caspase- 8 and the mitochondria-associated caspase-9 activates downstream caspases, such as caspase-3, leading to cell apoptosis (49). In the present study, it was revealed that dioscin markedly decreased the levels of Bcl-2, and upregulated the levels of Bax, cleaved-PARP and cleaved caspase-3/9. Overall, the aforementioned results indicated that dioscin induced its effects in A431 cells via ATM/p53 signaling to activate mitochondrial-mediated apoptosis.

MMPs are a family of proteins involved in the degradation of the extracellular matrix and the basement membrane component, and they are regarded as zinc-dependent proteinases that promote the invasion and metastasis of malignant tumors (50). Rho GTPases are a class of small GTP-binding proteins that belong to the Ras superfamily, and serve a crucial role in regulating cell migration, proliferation and apoptosis (51). The dysregulation of GTPases occurs in numerous types of human cancer, such as hepatocellular carcinoma, gastric cancer and prostate cancer, which contributes to local cancer cell proliferation and distant metastasis $(52,53)$. Notably, the results in the present study revealed that the expression levels of RHO, cdc42 and MMP2/9 were decreased by dioscin, which may inhibit the development and progression of tumor metastasis. Further transfection experiments using p53-siRNA in vitro revealed that p53-siRNA reversed the effects of dioscin on A431 cell colony formation, migration, apoptosis and DNA damage. In addition, p53 knockdown abrogated the effects of dioscin on the expression levels of cleaved caspase-3/9, cleaved-PARP, Bax, Bcl-2, $\mathrm{RHO}$ and cdc42, indicating that dioscin exerted anticancer effects against skin cancer cells via regulating p53 signaling.

Overall, the present study demonstrated that dioscin inhibited cell proliferation and migration, and induced apoptosis and DNA damage in human A431 cells through ATM/p53 signaling. Further research is required to investigate the underlying mechanisms, drug targets and clinical applications of dioscin against skin cancer.

\section{Acknowledgements}

Not applicable.

\section{Funding}

The present study was financially supported by the National Natural Science Foundation of China (grant nos. 81973735 and 81774184 ).

\section{Availability of data and materials}

The datasets used and/or analyzed during the current study are available from the corresponding author on reasonable request.

\section{Authors' contributions}

PW and CL designed the experiments and wrote the manuscript. PW and CW performed the cell experiments. PW performed the western blot assays. PW and CW performed the gene transfection experiments. PW and CL edited the manuscript. All authors read and approved the final manuscript.

\section{Ethics approval and consent to participate}

Not applicable.

\section{Patient consent for publication}

Not applicable.

\section{Competing interests}

The authors declare that they have no competing interests.

\section{References}

1. Trakatelli M, Ulrich C, del Marmol V, Euvrard S, Stockfleth E and Abeni D: Epidemiology of nonmelanoma skin cancer (NMSC) in Europe: Accurate and comparable data are needed for effective public health monitoring and interventions. Br J Dematol 156 (Suppl 3): S1-S7, 2007.

2. Karia PS, Han J and Schmults CD: Cutaneous squamous cell carcinoma: Estimated incidence of disease, nodal metastasis, and deaths from disease in the United States, 2012. J Am Acad Dermatol 68: 957-966, 2013.

3. Li Q, Peng YS, Chen PJ, Wang ML, Cao C, Xiong H, Zhang J, Chen MH, Peng XB and Zeng K: Peroxisome proliferator-activated receptor- $\gamma$ agonist-mediated inhibition of cell growth is independent of apoptosis in human epidermoid carcinoma A431 cells. Oncol Lett 15: 6578-6584, 2018.

4. Zhai XX, Ding JC, Tang ZM, Li JG, Li YC, Yan YH, Sun JC and Zhang CX: Effects of resveratrol on the proliferation, apoptosis and telomerase ability of human A431 epidermoid carcinoma cells. Oncol Lett 11: 3015-3018, 2016.

5. Li H, Tang Z, Chu P, Song Y, Yang Y, Sun B, Niu M, Qaed E, Shopit A, Han G, et al: Neuroprotective effect of phosphocreatine on oxidative stress and mitochondrial dysfunction induced apoptosis in vitro and in vivo: Involvement of dual PI3K/Akt and Nrf2/HO-1 pathways. Free Radic Biol Med 120: 228-238, 2018.

6. Afaq F and Katiyar SK: Polyphenols: Skin photoprotection and inhibition of photocarcinogenesis. Mini Rev Med Chem 11: 1200-1215, 2011.

7. Sajadimajd S, Bahramsoltani R, Iranpanah A, Kumar Patra J, Das G, Gouda S, Rahimi R, Rezaeiamiri E, Cao H, Giampieri F, et al: Advances on natural polyphenols as anticancer agents for skin cancer. Pharmacol Res 151: 104584, 2020.

8. Zhang Y, Xu Y, Qi Y, Xu L, Song S, Yin L, Tao X, Zhen Y, Han X, Ma X, et al: Protective effects of dioscin against doxorubicin-induced nephrotoxicity via adjusting FXR-mediated oxidative stress and inflammation. Toxicology 378: 53-64, 2017.

9. Xia Y, Jia C, Xue Q, Jiang J, Xie Y, Wang R, Ran Z, Xu F, Zhang Y and Ye T: Antipsychotic drug trifluoperazine suppresses colorectal cancer by inducing G0/G1 arrest and apoptosis. Front Pharmacol 10: 1029, 2019.

10. Yao H, Sun Y, Song S, Qi Y, Tao X, Xu L, Yin L, Han X, Xu Y, $\mathrm{Li} \mathrm{H}$, et al: Protective effects of dioscin against lipopolysaccharide-induced acute lung injury through inhibition of oxidative stress and inflammation. Front Pharmacol 8: 120, 2017.

11. Li XJ, Li ZF, Wang JJ, Han Z, Liu Z and Liu BG: Effects of microRNA-374 on proliferation, migration, invasion, and apoptosis of human SCC cells by targeting Gadd45a through P53 signaling pathway. Biosci Rep 37: BSR20170710, 2017.

12. Mao Z, Han X, Chen D, Xu Y, Xu L, Yin L, Sun H, Qi Y, Fang L, Liu K and Peng J: Potent effects of dioscin against hepatocellular carcinoma through regulating TP53-induced glycolysis and apoptosis regulator (TIGAR)-mediated apoptosis, autophagy and DNA damage. Br J Pharmacol 176: 919-937, 2019.

13. Si L, Xu L, Yin L, Qi Y, Han X, Xu Y, Zhao Y, Liu K and Peng J: Potent effects of dioscin against pancreatic cancer via miR-149-3P-mediated inhibition of the Akt1 signaling pathway. Br J Pharmacol 174: 553-568, 2017.

14. Sun D, Yu M, Li Y, Xing H, Gao Y, Huang Z, Hao W, Lu K, Kong C, Shimozato O, et al: Histone deacetylase 2 is involved in DNA damage-mediated cell death of human osteosarcoma cells through stimulation of the ATM/p53 pathway. FEBS Open Bio 9: 478-489, 2019. 
15. Lavin MF and Kozlov S: ATM activation and DNA damage response. Cell Cycle 6: 931-942, 2007.

16. Hsu YL, Chia CC, Chen PJ,Huang SE, Huang SC and Kuo PL: Shallot and licorice constituent isoliquiritigenin arrests cell cycle progression and induces apoptosis through the induction of ATM/p53 and initiation of the mitochondrial system in human cervical carcinoma HeLa cells. Mol Nutr food Res 53: 826-835, 2009.

17. Tao X, Sun X, Yin L, Han X, Xu L, Qi Y, Xu Y, Li H, Lin Y, Liu K and Peng J: Dioscin ameliorates cerebral ischemia/reperfusion injury through the downregulation of TLR4 signaling via HMGB-1 inhibition. Free Radical Bio Med 84: 103-115, 2015.

18. Sun M, Ren J, Du H, Zhang Y, Zhang J, Wang S and He L: A combined A431 cell membrane chromatography and online high performance liquid chromatography /mass spectrometry method for screening compounds from total alkaloid of Radix Caulophylli acting on the human EGFR. J Chromatogr B Analyt Technol Biomed Life Sci 878: 2712-2718, 2010.

19. Pliskova M, Vondracek J, Kren V, Gazak R, Sedmera P, Walterova D, Psotova J, Simanek V and Machala M: Effects of silymarin flavonolignans and synthetic silybin derivatives on estrogen and aryl hydrocarbon receptor activation. Toxicology 215: 80-89, 2005.

20. Zhao L, Tao X, Qi Y, Xu L, Yin L and Peng J: Protective effect of dioscin against doxorubicin-induced cardiotoxicity via adjusting microRNA-140-5p-mediated myocardial oxidative stress. Redox Bio 16: 189-198, 2018

21. Yao H, Tao X, Xu L, Qi Y, Yin L, Han X, Xu Y, Zheng L and Peng J: Dioscin alleviates non-alcoholic fatty liver disease through adjusting lipid metabolism via SIRT1/AMPK signaling pathway. Pharmacol Res 131: 51-60, 2018.

22. Hu Y, Mao Z, Xu L, Yin L, Tao X, Tang Z, Qi Y, Sun P and Peng J: Protective effect of dioscin against intestinal ischemia/reperfusion injury via adjusting miR-351-5p-mediated oxidative stress. Pharmacol Res 137: 56-63, 2018

23. Zheng L, Han X, Hu Y, Zhao X, Yin L, Xu L, Qi Y, Xu Y, Han X, Liu K and Peng J: Dioscin ameliorates intestinal ischemia/ reperfusion injury via adjusting miR-351-5p/MAPK13-mediated inflammation and apoptosis. Pharmacol Res 139: 431-439, 2019.

24. Qiao Y, Xu L, Tao X, Yin L, Qi Y, Xu Y, Han X, Tang Z, Ma X, Liu K and Peng J: Protective effects of dioscin against fructose-induced renal damage via adjusting Sirt3-mediated oxidative stress, fibrosis, lipid metabolism and inflammation. Toxicol Lett 284: 37-45, 2018.

25. Zheng L, Yin L, Xu L, Qi Y, Li H, Xu Y, Han X, Liu K and Peng J: Potective effect of dioscin against thioacetamide-induced acute liver injury via FXR/AMPK signaling pathway in vivo. Biomed Pharmacother 97: 481-488, 2018

26. Yin L, Qi Y, Xu Y, Xu L, Han X, Tao X, Song S and Peng J: Dioscin inhibits HSC-T6 cell migration via adjusting SDC-4: Insights from iTRAQ-based quantitative proteomics. Front Pharmacol 8: 665, 2017.

27. Zhang Y, Tao X, Yin L, Xu L, Xu Y, Qi Y, Han X, Song S Zhao Y, Lin Y, et al: Protective effects of dioscin against cisplatin-induced nephrotoxicity via regulating miR-34a/Sirt1 signal pathway. Br J Pharmacol 174: 2512-2527, 2017

28. Yao H, Xu Y, Yin L, Tao X, Xu L, Qi Y, Han X, Sun P, Liu K and Peng J: Dioscin protects ANIT-induced intrahepatic cholestasis through regulating transporters, apoptosis and oxidative stress. Front Pharmacol 8: 116, 2017.

29. Hu Y, Tao X, Han X, Xu L, Yin L, Qi Y, Zhao Y, Xu Y, Wang C and Peng J: Dioscin attenuates gastric ischemia/reperfusion injury through the down-regulation of PKC/ERK1/2 signaling via PKCa and PKCB2 inhibition. Chem Bio Interact 258: 234-244, 2016.

30. Qi M, Yin L, Xu L, Tao X, Qi Y, Han X, Wang C, Xu Y, Sun H, Liu K and Peng J: Dioscin alleviates lipopolysaccharide-induced inflammatory kidney injury via the microRNA let-7i/TLR4/MyD88 signaling pathway. Pharmacol Res 111: 509-522, 2016.

31. Tao X, Yin L, Xu L and Peng J: Dioscin: A diverse acting natural compound with therapeutic potential in metabolic diseases, cancer, inflammation and infections. Pharmacol Res 137: 259-269, 2018.

32. Zhao X, Yin L, Fang L, Xu L, Sun P, Xu M, Liu K and Peng J: Protective effects of dioscin against systemic inflammatory response syndromevia adjusting TLR2/MyD88/NF- $\kappa b$ signal pathway. Int Immunopharmacol 65: 458-469, 2018.

33. Lv L, Zheng L, Dong D, Xu L, Yin L, Xu Y, Qi Y, Han X and Peng J: Dioscin, a natural steroid saponin, induces apoptosis and DNA damage through reactive oxygen species: A potential new drug for treatment of glioblastoma multiforme. Food Chem Toxicol 59: 657-669, 2013.
34. Si L, Zheng L, Xu L, Yin L, Han X, Qi Y, Xu Y, Wang C and Peng J: Dioscin suppresses human laryngeal cancer cells growth via induction of cell-cycle arrest and MAPK-mediated mitochondrial-derived apoptosis and inhibition of tumor invasion. Eur J Pharmacol 774: 105-117, 2016.

35. Tao X, Xu L, Yin L, Han X, Qi Y, Xu Y, Song S, Zhao Y and Peng J: Dioscin induces prostate cancer cell apoptosis through activation of estrogen receptor- $\beta$. Cell Death Dis 8: e2989, 2017.

36. Wei Y, Xu Y, Han X, Qi Y, Xu L, Xu Y, Yin L, Sun H, Liu K and Peng J: Anti-cancer effects of dioscin on three kinds of human lung cancer cell lines through inducing DNA damage and activating mitochondrial signal pathway. Food Chem Toxicol 59: $118-128,2013$.

37. Zhao X, Tao X, Xu L, Yin L, Qi Y, Xu Y, Han X and Peng J: Dioscin induces apoptosis in human cervical carcinoma HeLa and $\mathrm{SiHa}$ cells through ROS-mediated DNA damage and the mitochondrial signaling pathway. Molecules 21: 730, 2016.

38. Zhao X, Xu L, Zheng L, Yin L, Qi Y, Han X, Xu Y and Peng J: Potent effects of dioscin against gastric cancer in vitro and in vivo. Phytomedicine 23: 274-282, 2016.

39. Kou Y, Ji L, Wang H, Wang W, Zheng H, Zhou J, Liu L, Qi X, Liu Z, Du B and Lu L: Connexin 43 upregulation by dioscin inhibits melanoma progression via suppressing malignancy and inducing M1 polarization. Int J Cancer 141: 1690-1703, 2017.

40. Wang Y, Fu M, Liu J, Yang Y, Yu Y, Li J, Pan W, Fan L, Li G, Li $\mathrm{X}$ and Wang $\mathrm{X}$ : Inhibition of tumor metastasis by targeted daunorubicin and dioscin codelivery liposomes modified with PFV for the treatment of non-small-cell lung cancer. Int J Nanomedicine 14: 4071-4090, 2019

41. Zeng N, Hongbo T, Xu Y, Wu M, Wu Y: Anticancer activity of caffeic acid nbutyl ester against A431 skin carcinoma cell line occurs via induction of apoptosis and inhibition of the mTOR/ PI3K/AKT signaling pathway. Mol Med Rep 17: 5652-5657, 2018.

42. Zhao J, Xu Y, Wang C, Ding Y, Chen M, Wang Y, Peng J, Li L and Lv L: Soluplus/TPGS mixed micelles for dioscin delivery in cancer therapy. Drug Dev Ind Pharm 43: 1197-1204, 2017.

43. Zhang Z, Wang CZ, Du GJ, Qi LW, Calway T, He TC, Du W and Yuan CS: Genistein induces G2/M cell cycle arrest and apoptosis via ATM/p53-dependent pathway in human colon cancer cells. Int J Oncol 43: 289-296, 2013.

44. Ling G, Ahmadian A, Persson A, Unden AB, Afink G, Williams C, Uhlén M, Toftgård R, Lundeberg J and Pontén F: PATCHED and p53 gene alterations in sporadic and hereditary basal cell cancer. Oncogene 53: 7770-7778, 2001.

45. Chang IY, Kim JH, Park KH and Yoon SP: Experimental varicocele induces p53-dependent germ cell apoptosis through activation of $\gamma$-H2AX. Urol Int 85: 216-220, 2010

46. Lee CF, Yang JS, Tsai FJ, Chiang NN, Lu CC, Huang YS, Chen C and Chen FA: Kaempferol induces ATM/p53-mediated death receptor and mitochondrial apoptosis in human umbilical vein endothelial cells. Int J Oncol 48: 2007-2014, 2016.

47. Maira F, Catania A, Candido S, Russo AE, McCubrey JA, Libra M, Malaponte G and Fenga C: Molecular targeted therapy in melanoma: A way to reverse resistance to conventional drugs. Curr Drug Deliv 9: 17-29, 2012

48. Liu J, Yin S, Reddy N, Spencer C and Sheng S: Bax mediates the apoptosis-sensitizing effect of maspin. Cancer Res 64: 1703-1711, 2004.

49. Nikolaou V, Stratigos A, Bafaloukos D and Katsambas A: Antiangiogenic and antiapoptotic treatment in advanced melanoma. Clin Dermatol 31: 257-263, 2013

50. Sarig-Nadir O and Seliktar D: The role of matrix metalloproteinases in regulating neuronal and nonneuronal cell invasion into PEGylated fibrinogen hydrogels. Biomaterials 31: 6411-6416, 2010.

51. Zhu Y, Zhou J, Xia H, Chen X, Qiu M, Huang J, Liu S, Tang Q, Lang N, Liu Z, et al: The Rho GTPase RhoE is a p53-regulated candidate tumor suppressor in cancer cells. Int J Oncol 44: 896-904, 2014

52. Takeba Y, Matsumoto N, Watanabe M, Takenoshita-Nakaya S, Ohta Y, Kumai T, Takagi M, Koizumi S, Asakura T and Otsubo T: The Rho kinase inhibitor fasudil is involved in p53-mediated apoptosis in human hepatocellular carcinoma cells. Cancer Chemother Pharmacol 69: 1545-1555, 2012.

53. Dornan D, Shimizu H, Mah A, Dudhela T, Eby M, O'rourke K, Seshagiri S and Dixit VM: ATM engages autodegradation of the E3 ubiquitin ligase COP1 after DNA damage. Science 313: 1122-1126, 2006.

This work is licensed under a Creative Commons Attribution-NonCommercial-NoDerivatives 4.0 International (CC BY-NC-ND 4.0) License. 